\title{
Design and Analysis of Nanchong Sports Public Service Information Platform Based on Multiobjective Optimization
}

\author{
Dujuan Li (iD \\ Department of Physical Education, North Sichuan Medical College, Nanchong, Sichuan 637000, China \\ Correspondence should be addressed to Dujuan Li; yangyang0809@nsmc.edu.cn
}

Received 5 November 2021; Revised 10 December 2021; Accepted 3 January 2022; Published 7 February 2022

Academic Editor: Hangjun Che

Copyright $\odot 2022$ Dujuan Li. This is an open access article distributed under the Creative Commons Attribution License, which permits unrestricted use, distribution, and reproduction in any medium, provided the original work is properly cited.

\begin{abstract}
Through the design and analysis of the Nanchong sports public service information platform, we can see that in order to improve the city's sports public service, we should improve the sports public service according to the factors such as the amount of activities, funds, and promotion. In view of the multiobjective optimization of sports public service in Nanchong City, the century establishment and analysis of the information platform were carried out. Its information platform includes intelligent venues, information platforms, sports safety, and other topics so as to achieve the purpose of healthy sports and relaxed sports, improve Nanchong people's sports interest and experience as a whole, and enhance satisfaction. In order to alleviate the financial difficulties, relevant departments can carry out public welfare activities to sponsor sports public services in Nanchong City. According to the investigation, $29.4 \%$ of the randomly asked citizens have high satisfaction, $32.3 \%$ have no experience, and $16.5 \%$ are dissatisfied, which shows once again that Nanchong people have low awareness of the sports public service platform. In order to realize the good development of sports public service in this city, we should comprehensively promote the development of sports public service and improve citizens' awareness, experience, and satisfaction.
\end{abstract}

\section{Introduction}

Through the design and analysis of the sports public service platform under multiobjective optimization in Nanchong City, it is known that the related platform can improve Nanchong citizens' awareness and participation in sports public service. At the same time, through the analysis of data, it is known that there are still many imperfect developments in sports public services in Nanchong City, which should be continuously improved and popularized in a large area through relevant influencing factors so as to improve people's awareness and solve related problems such as scarce funds, venues, and activities. By analyzing the problems in the public sports services in Nanchong City and analyzing and explaining the related factors of the problems, we can improve the public sports services in Nanchong City.

Literature [1] proposes a multiobjective evolutionary algorithm with nondominant ranking because of its nonelitist computational complexity and specified shared parameters. In order to solve the difficulties while speeding up the nondominant sorting method, a selection operator is proposed to establish a mating pool by selecting $\mathrm{N}$ best solutions with the combined parent-child population. Literature [2] makes the combination of multiple objectives form scalar objective function temporarily by the linear combination of multiple objectives and transforming the objectives into constraints. It shows the ability of maintaining diversification in the open problem of a water conservancy system. Literature [3] proves the effectiveness of the multiobjective algorithm in dealing with more than two objective problems by constructing the optimal frontier with simplicity, an arbitrary number of decision variables, and positions. Literature [4] uses advanced algorithms to solve two or more conflicting objective function problems, which is the related ability of "evolutionary multiobjective optimization." Therefore, we research and develop the most representative algorithms and applications through the relevant historical framework. The advantages, fields, and future trends of related algorithms are discussed. Literature [5] uses a supply chain network (SCN) to design the optimal 
solution of the problem efficiently and effectively in order to solve the multiobjective conflicts such as cost and resource utilization. In this paper, the actual data of Turkish Plastics Company are studied in two stages and solved by SCN. In literature [6], the development of sports public service is based on its main basic characteristics and basic structure. Literature [7] combines sports public service with economics and practice, understands the imbalance and incompleteness of sports public service development, and enhances the sustainability of sports public service development. In literature [8], the sports public service usually represents the comprehensive strength of sports and enhances the transformation of sports public service. In literature [9], at present, fairness, public welfare, diversity, convenience, and high efficiency are the characteristics of sports public service in the development stage. To build people-oriented sports public service value is the goal and mission of developing sports public service. Literature [10] simplifies the data of sports public service through VER (Building Sports Public Service) model and understands the influence of the sports public service field. The design and analysis method of the information platform in literature [11] is one of the main development directions of digital campus. Literature [12] aims at the shortcomings of urban and rural sports public services, including the differences in facilities, to promote the development of rural sports public services so as to achieve balanced development. Literature [13] improves the accuracy of parts by considering different objectives. By collecting the objective function to assign the weight of part precision, the part precision can be better grasped to achieve the specified precision. High quality of parts and high efficiency of construction are ensured. Literature [14] studies public services through literature and related laws, including establishing legal status, reward and punishment system, and evaluation system. In literature [15], the information platform of cloud computing is a new method of sharing facilities at present. The second part of the article puts forward corresponding solutions to the current multiobjective problems; the third part puts forward the theoretical basis of the multiobjective model. The fourth part designs and analyzes the methods proposed in this paper.

\section{Multiobjective Problem Solving}

2.1. Content of Multiobjective Solution Problem. Figure 1 shows a multiobjective feasible solution. The feasible solution includes the infeasible solution and the Pareto optimal solution, and the optimal solution includes the satisfactory solution. To solve a multiobjective problem, multiple objectives are usually transformed into one objective, among which there are many solutions, such as the ideal point method, linear weighting method, maximum-minimum method, goal programming method, and fuzzy digital solution [16], as shown in Figure 1.

2.1.1. Pareto Sorting and Genetic Algorithm Solving Steps. Pareto chart is a chart used to arrange quality problems and quality improvement items in order of importance. It is

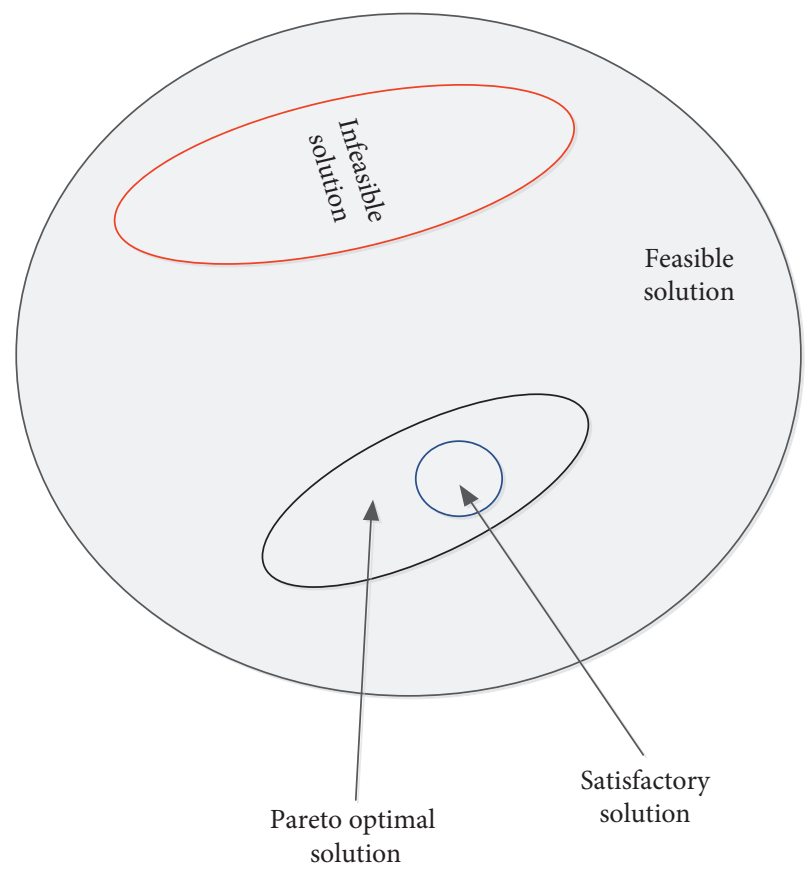

FIgURE 1: Schematic diagram of multiobjective solution.

named after the Italian economist $V$. Pareto. A Pareto chart, also called permutation chart and primary and secondary chart, is a histogram drawn in order of frequency of occurrence, indicating how many results are caused by confirmed types or categories. The steps are as follows: inputting initial parameters and carrying out initial inference, carrying out various target calculations and discussions, carrying out genetic suboperation to generate degrees of freedom after completion, and then judging by $g=G$, if the output is the Pareto optimal solution, calculating the corresponding target value, and finally outputting it in graphic mode; otherwise, the loop is repeated according to the prompt, as shown in Figure 2.

2.1.2. NSGA-II Algorithm Steps. The NSGA-II algorithm was proposed by Srinivas and Deb on the basis of NSGA in 2000. It is superior to the NSGA algorithm; it uses a fast nondominated sorting algorithm, and the computational complexity is greatly reduced than that of NSGA. Its use creates congestion and crowding. The degree comparison operator replaces the shared radius shareQ that needs to be specified and is used as the winning criterion in the samelevel comparison after quick sorting so that the individuals in the quasi-Pareto domain can be extended to the entire Pareto domain and distributed evenly, maintaining the population's diversity; the introduction of the elite strategy expands the sampling space, prevents the loss of the best individuals, and improves the calculation speed and robustness of the algorithm. At first, a value is assigned, the order is changed into a set, the value is reassigned, the number is judged whether it is equal to the maximum algebra, it is output if it is equal and rejudged if it is not equal, as shown in Figure 3. 


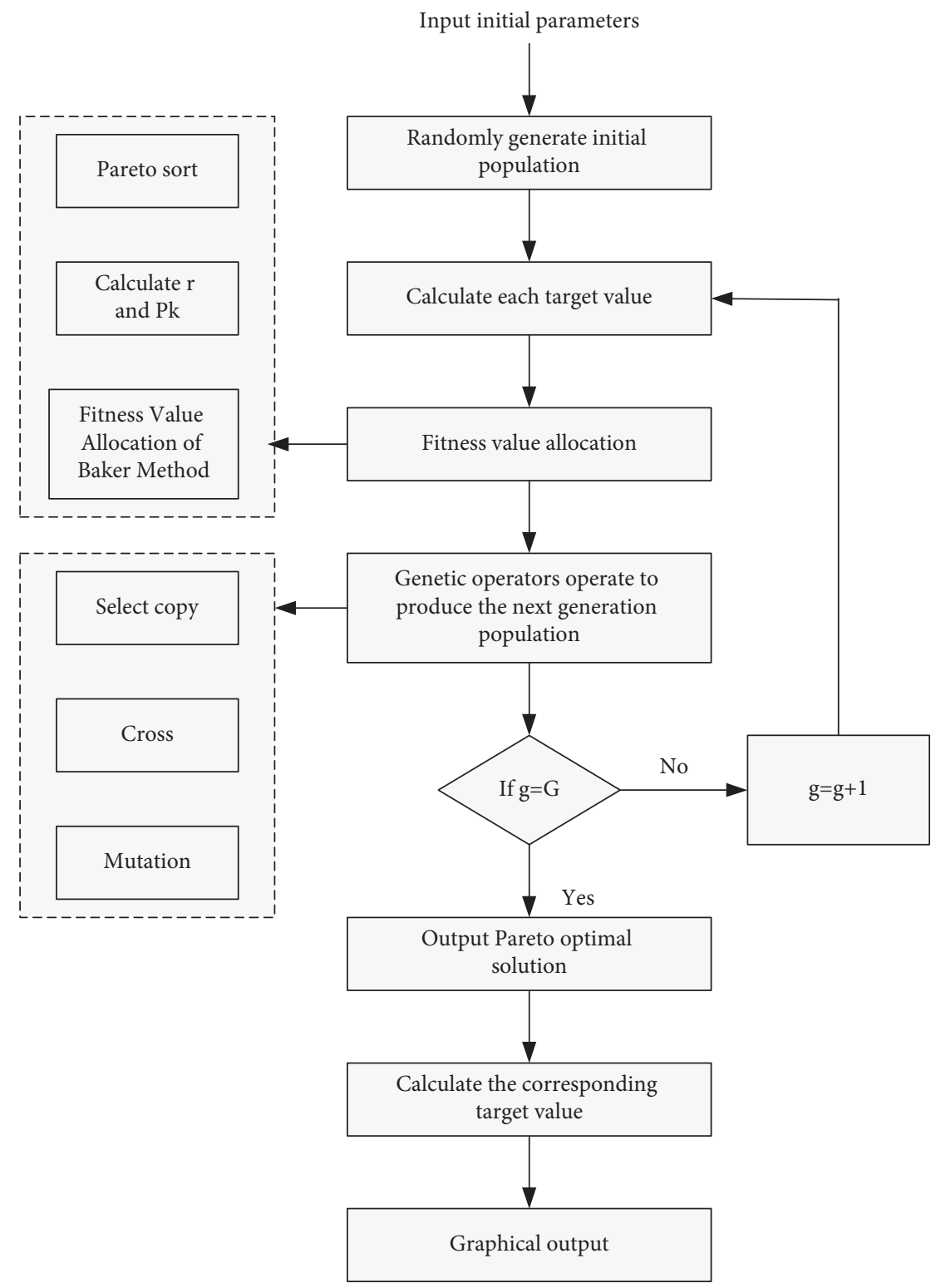

Figure 2: Solution step diagram.

\subsection{Design of Sports Public Service Platform}

2.2.1. Sports Public Service Content. In order to facilitate Nanchong citizens' sports awareness and improve sports duration and frequency, better planning is carried out through platform design and analysis.

2.2.2. Platform Design. As shown in Figure 4, the sports public service platform is designed through payment methods, understanding methods, participation methods, security, and other aspects. The establishment of smart venues can facilitate the use of Nanchong citizens, and the specific contents of sports activities can be understood through web pages and small programs and ensure the safety of citizens' sports by means of video surveillance.

\section{Multiobjective Optimization Model}

\subsection{Multiobjective Optimization}

\subsubsection{Multiobjective Mathematical Description.}

$$
\begin{gathered}
\operatorname{Min}(\& \operatorname{Max}) y=f(x)=\left[f_{1}(x), f_{2}(x), \ldots, f_{n}(x)\right] \\
\text { s.t. }\left\{\begin{array}{l}
g(x)=\left[g_{1}(x), g_{2}(x), \ldots, g_{k}(x)\right] \leq 0, \\
h(x)=\left[h_{1}(x), h_{2}(x), \ldots, h_{m}(x)\right]=0, \\
x=\left[x_{1}, x_{2}, \ldots, x_{d}, \ldots, x_{d}\right] \\
x_{d_{-} \text {min }} \leq x_{d} \leq x_{d_{-} \max }(d=1,2, \ldots, D) .
\end{array}\right.
\end{gathered}
$$

In formula (1), $f(x)$ is the maximum or minimum value 


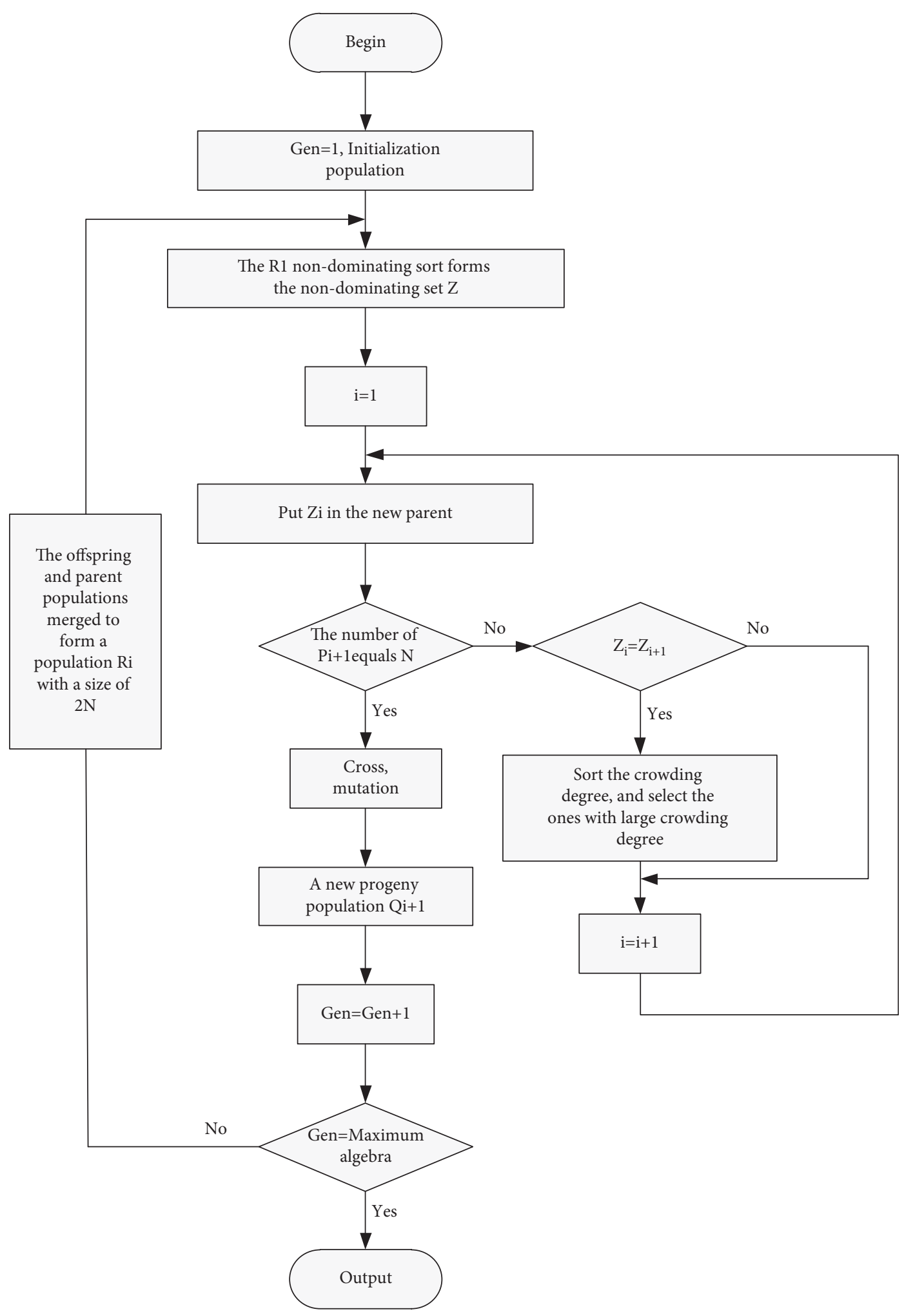

FIgURE 3: NSGA-II algorithm step diagram. 


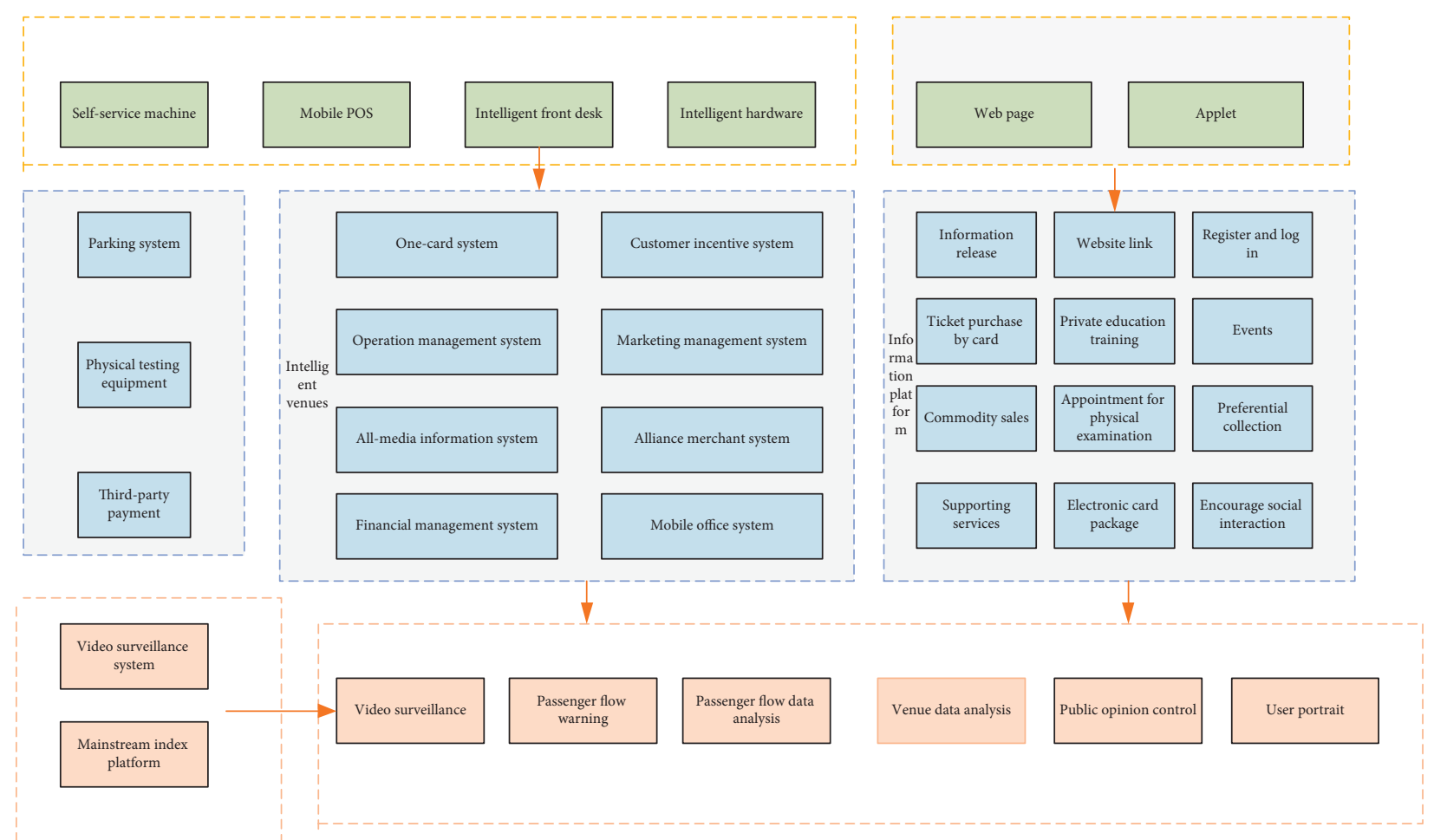

FIgURE 4: Design drawing of sports public service platform.

of the objective function, and formula (2) is the corresponding conditional constraint to formula (1).

\subsubsection{Fast Nondominated Sorting. Quick nondominated} sorting stratifies the individuals in the population, the best individual is in the first layer, and then in addition to the first layer, nondominated individuals are found from the rest of the individuals, and so on. Sp refers to an individual dominated by $p$, that is, an individual with no outstanding individual. Fast nondominant sorting sorts the population according to the dominant relationship among individuals [17]. Each individual corresponds to two parameters, $n_{i}$ and $s_{i}$. The individual with $n_{i}$ being 0 is stored in the set $F 1$, and if $n_{i}$ is subtracted by 1 , the result is 0 , which is stored in the set F2., where $m$ is the number of objective functions, and $n$ is the population size in Algorithm 1.

3.1.3. Crowding Degree. The calculation of the congestion coefficient needs to sort the population according to the ascending order of the value of each objective function (that is, if the first-level nondominated layer is obtained, it is sorted according to the size of the objective function, and then the congestion degree is calculated). The perimeter of the largest rectangle formed in Figure 5 is the desired result.

The smaller nondominant level is dominant [13]; when the nondominant levels are the same, the individuals with greater congestion are dominant in Algorithm 2.
3.1.4. NGA-II Process. The process is first initialized, and then the data are judged according to the process [18], as shown in Figure 6.

3.2. Multiobjective Optimization Problem Model. Taking the minimization problem as an example, the equation is as follows:

$$
\begin{aligned}
\min F(x) & =\left(f_{1}(x), f_{2}(x), \ldots, f_{m}(x)\right)^{T}, \\
\text { subject to } x & \in \Omega \subseteq R^{n},
\end{aligned}
$$

where $M$ is the scale of the objective function, $\Omega$ is the decision variable, and $f(x)$ is the objective function [19], as shown in Figure 7.

(1) Pareto dominates:

$$
\left\{\begin{array}{l}
\forall i \in\{1,2, \ldots, m\}, f_{i}(x) \leq f_{i}(y), \\
\exists j \in\{1,2, \ldots, m\}, f_{j}(x)<f_{j}(y) .
\end{array}\right.
$$

(2) Pareto nondominated solution: there is no corresponding solution set.

(3) Pareto optimal solution set:

$$
\mathrm{PS}=\{x \in \Omega \mid y \in \Omega, y \prec x\} .
$$

(4) Pareto's best frontier:

$$
\mathrm{PF}=\{F(x) \mid x \in \mathrm{PS}\} .
$$


for each $p \in P$

if $(p>q)$ then // If $P$ dominates $Q$

$S p=S p \cup\{q\} / /$ Add $q$ to $S p$

else if $(q>p)$ then // If $P$ is dominated by $Q$

$n p=n p+1 / / N p$ plus 1

If $n p=0$ then // If $P$ is not dominated

$F 1=F 1 \cup\{p\} / / P$ is a member of the first frontier

$i=1$

While $F i \neq \phi$

$H=\phi$

for each $p \in F i / /$ For every $p$ in $F i$

for each $q \in S p / /$ For each $q$ in $S p$

$n q=n q-1 / / N q$ minus 1

if $n q==0$

then $H=H \cup\{q\}$

$i=i+1$

$F i=H / /$ Current frontier

Algorithm 1: Fast nondominated sorting.

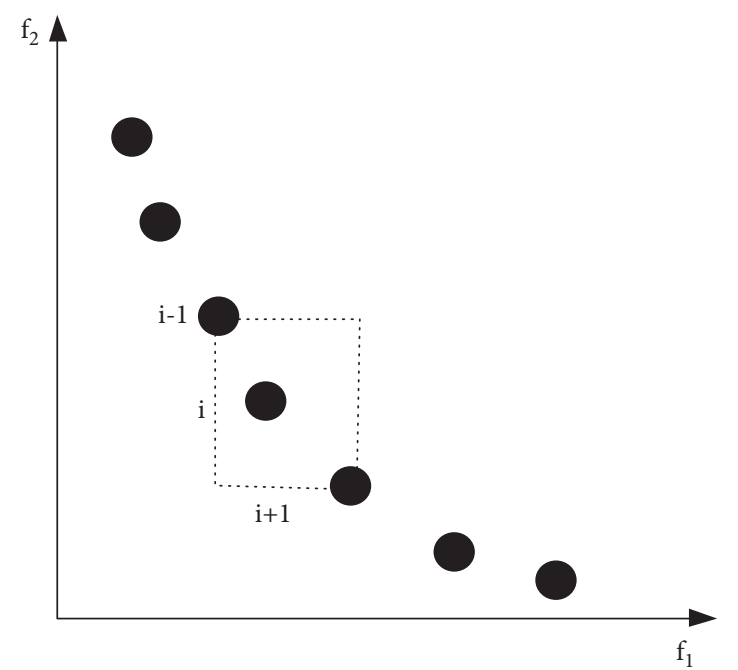

Figure 5: Schematic diagram of crowding degree.

$j=|L|$

for each $I$, set $L[i]$ distance $=0 / /$ Initialization distance

for each objective $m$

$L=$ sort $(L, \mathrm{~m}) / /$ Sort by each target value

$L[1]$ distance $=L[j]$ distance $=\infty / /$ Always keep boundary points for $i \leftarrow 2$ to $j-1$

$L[i]$ distance $=L[i]$ distance $+(L[i+1] . m-\mathrm{L}[i-1] . m)$

Algorithm 2: Congestion distance algorithm. 


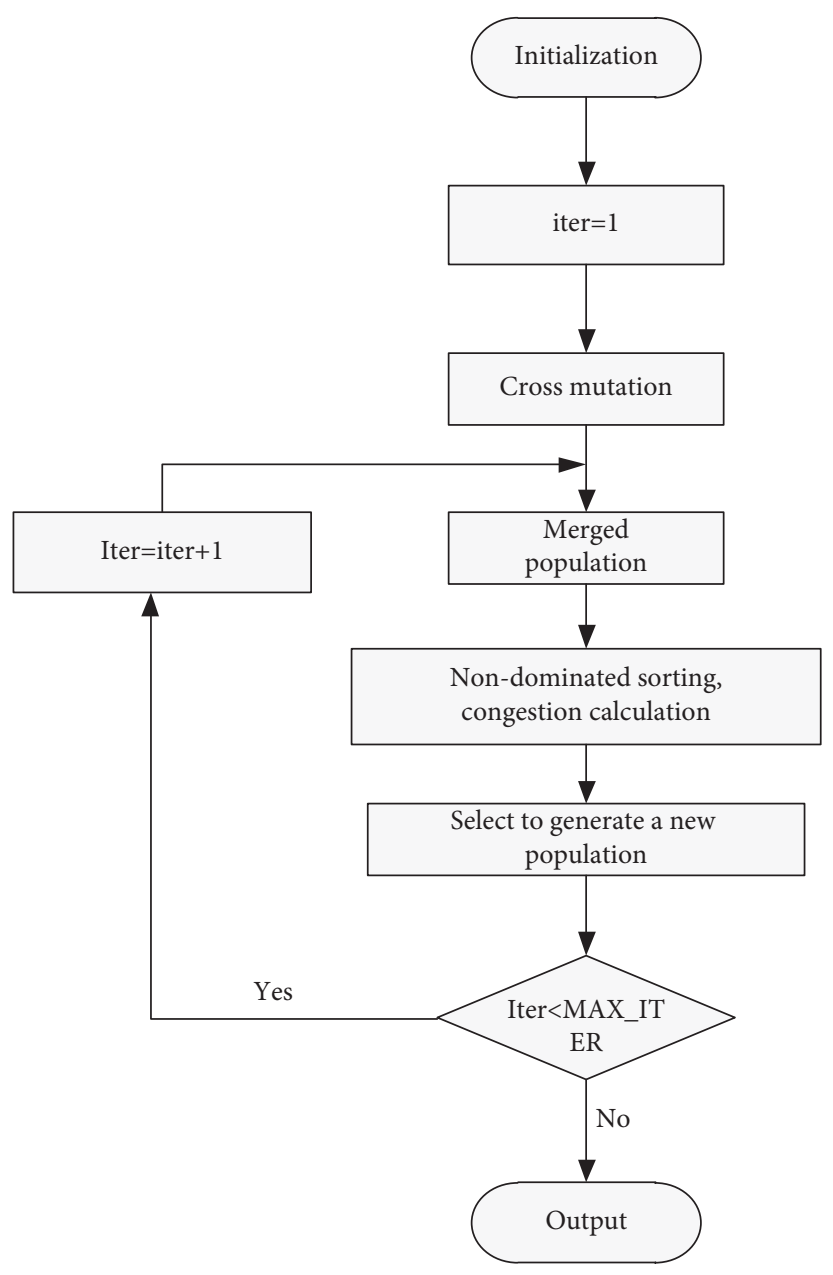

Figure 6: NSGA-II flowchart.

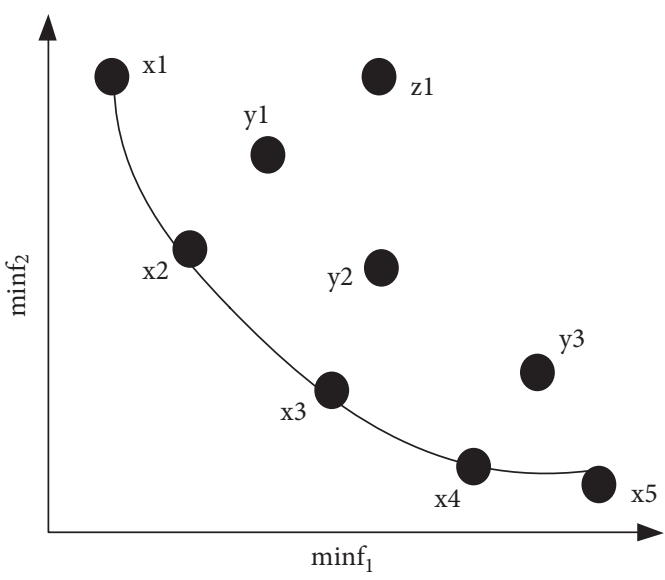

Figure 7: Pareto model diagram. 
(5) Convergence: it refers to the proximity of the optimal frontier of Pareto's optimal solution [20].

(6) Diversity: Pareto optimal solution and dispersion of real frontier [21].

\subsection{Basic Theory of Multiobjective Optimization.}

Among them, $X=\left[x_{1}, x_{i}, \ldots, x_{m}\right]^{T}, M$ is the decision variable. Equation (7) is the minimum value of the objective function, and equation (8) is the objective function constraint.

3.4. Basic Concepts of MOEA. The general form of MOEA and MOP is as follows [22]:

$$
\begin{aligned}
\min f(x) & =\left[f_{1}(x), f_{2}(x), \ldots, f_{M}(x)\right]^{T}, \\
g_{j}(x) & \geq 0, j=1,2, \ldots, p, \\
h_{k}(x) & =0, k=1,2, \cdots, q, \\
x_{i}^{l} \leq x_{i} \leq_{i}^{u}, i & =1,2, \ldots, n .
\end{aligned}
$$

$$
\forall m \in\{1, \ldots, M\} f_{m}(\mu) \leq f_{m}(v), \exists m \in\{1,2, \ldots, M\} \text { Satisfy } f_{m}(\mu)<f_{m}(v) \text { then } \mu<v
$$

(2) Pareto optimal solution

$$
P^{*}=\left\{x \in \Omega \mid \exists x^{\prime} \in \Omega, f\left(x^{\prime}\right)<f(x)\right\} .
$$

(3) Pareto optimal frontier

$$
\mathrm{PF}^{*}=\left\{f(x), x \in P^{*}\right\} \text {. }
$$

3.4.1. Function Performance Evaluation. GD: average minimum distance from each point in $P$ to $P^{*}$.

$$
\mathrm{GD}\left(P, P^{*}\right)=\frac{\sqrt{\sum_{y \in P} \min _{x \in P *} \operatorname{dis}(x, y)^{2}}}{|p|} .
$$

IGD: reference point to nearest individual mean.

$$
\operatorname{IGD}\left(P, P^{*}\right)=\frac{\sum_{x \in P} \min _{y \in P} \operatorname{dis}(x, y)}{\left|P^{*}\right|} .
$$

Spacing: standard deviation to minimum distance [23].

$$
\operatorname{Spacing}(P)=\sqrt{\frac{1}{|p|-1} \sum_{i=1}^{|p|}\left(\bar{d}-d_{i}\right)^{2}} .
$$

DM: width of all solution sets as follows:

$$
\Delta=\frac{d_{f}+d_{i}+\sum_{i=1}^{N-1}\left|d_{i}-\bar{d}\right|}{d_{f}+d_{i}+(N-1) \bar{d}} .
$$

$\mathrm{HV}$ : nondominated front surface and reference point forming area hypervolume [24] are as follows:

$$
\mathrm{HV}=\delta\left(\bigcup_{i=1}^{|s|} v_{i}\right)
$$

3.5. Static Multiobjective Optimization Algorithm. MOEA/D

(1) Weighted method:

$$
\begin{aligned}
& \text { Minimize } g^{\mathrm{ws}}(x \mid \lambda)=\sum_{i=1}^{m} \lambda_{i} f_{i}(x), \\
& \text { s.t. } x \in \Omega
\end{aligned}
$$

(2) Chebyshev method:

$$
\text { Minimize } g^{\text {te }}\left(x \mid \lambda, z^{*}\right)=\max _{1 \leq i \leq m}\left\{\lambda_{i}\left|f_{i}(x)-z_{i}^{*}\right|\right\},
$$$$
\text { s.t. } x \in \Omega \text {. }
$$ 
(3) Bondary intersection method:

$$
\text { Minimize } g^{\text {bip }}\left(x \mid \lambda, z^{*}\right)=d_{1}+\theta d_{2},
$$

subject to $x \in \Omega$

$$
\begin{aligned}
& d_{1}=\frac{\left\|\left(z^{*}-F(X)\right)^{\tau} \lambda\right\|}{\|\lambda\|}, \\
& d_{2}=\left\|F(x)-\left(z^{*}-d_{1} \lambda\right)\right\| .
\end{aligned}
$$

\section{Design and Analysis of Sports Public Service Platform in Nanchong City}

\subsection{Analysis on the Present Situation of Sports Public Service}

4.1.1. List of Sports Public Service Efficiency in Different Regions. Through Table 1 and Figure 8, we know that Chengdu ranks first in the efficiency of sports public service among Chengdu, Nanchong, Yibin, and Zigong. Nanchong City followed closely in the second place. In contrast, the efficiency of sports public service in Zigong is low. Since 2013-2017, the average efficiency of sports public services in the four cities surveyed is about 0.751 , which is a good situation. The maximum value is 1.000 , and the minimum value is 0.643 , which has a big gap. Therefore, it is analyzed that the efficiency of public service is seriously differentiated. We should know that the factors affecting the efficiency through investigation improve the efficiency of sports public service in Nanchong from many aspects. Combined with Figure 8, it can be seen that the development efficiency of sports public services in the four cities investigated in recent years is gentle and has not changed much, so we should investigate from many aspects to further improve the efficiency of sports public services. The related efficiency of sports public services in the surveyed cities can be clearly seen through the list of sports public service efficiency. Regarding the source of funds for public sports services in Nanchong City, it can be seen that organizing sports competitions accounts for the largest proportion. Through the investigation and analysis of public sports services in Nanchong City, it is found that the lack of professional guidance accounts for the largest proportion of the reasons for the lack of development. In order to improve this factor, a large number of professional instructors should be trained in many places.

4.1.2. Investigation of Sports Public Service Supply in Nanchong City. It can be seen from Figure 9 that the management contents of the Nanchong sports public service platform include financial support, sports venue management, sports activity organization management, sports competition organization, and publicity of beneficial knowledge of physical exercise. Among them, organizing sports competitions accounts for $30.20 \%$ of the public service platform, while the financial support is only $7.88 \%$, so sports public services are also facing problems such as insufficient financial management.
TABLE 1: List of sports public service efficiency.

\begin{tabular}{lcccccc}
\hline & 2013 & 2014 & 2015 & 2016 & 2017 & Ranking \\
\hline Chengdu & 0.830 & 0.833 & 0.960 & 1.000 & 0.994 & 1 \\
Nanchong & 0.634 & 0.798 & 0.823 & 0.790 & 0.770 & 2 \\
Yibin & 0.669 & 0.721 & 0.660 & 0.587 & 0.664 & 3 \\
Zigong & 0.654 & 0.590 & 0.660 & 0.700 & 0.690 & 4 \\
Average & 0.699 & 0.736 & 0.776 & 0.770 & 0.780 & 5 \\
Minimum & 0.643 & 0.590 & 0.660 & 0.587 & 0.664 & \\
Maximum & 0.830 & 0.833 & 0.960 & 1.000 & 0.994 & \\
\hline
\end{tabular}

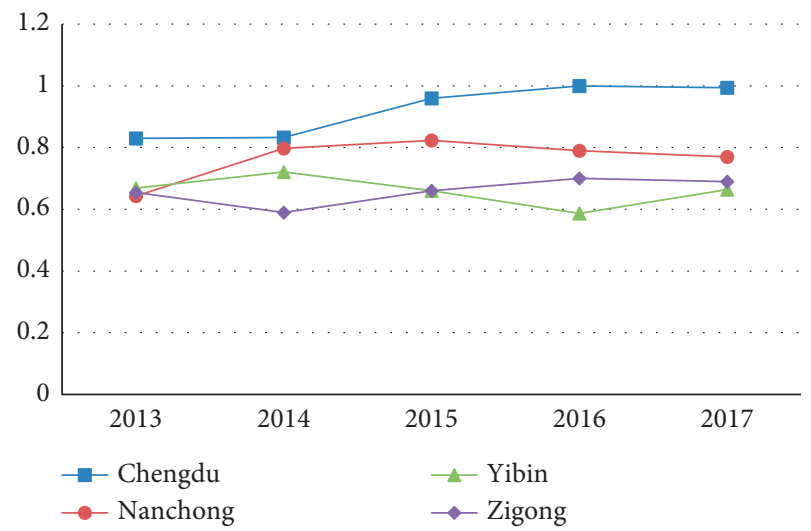

Figure 8: Efficiency comparison chart of four cities.

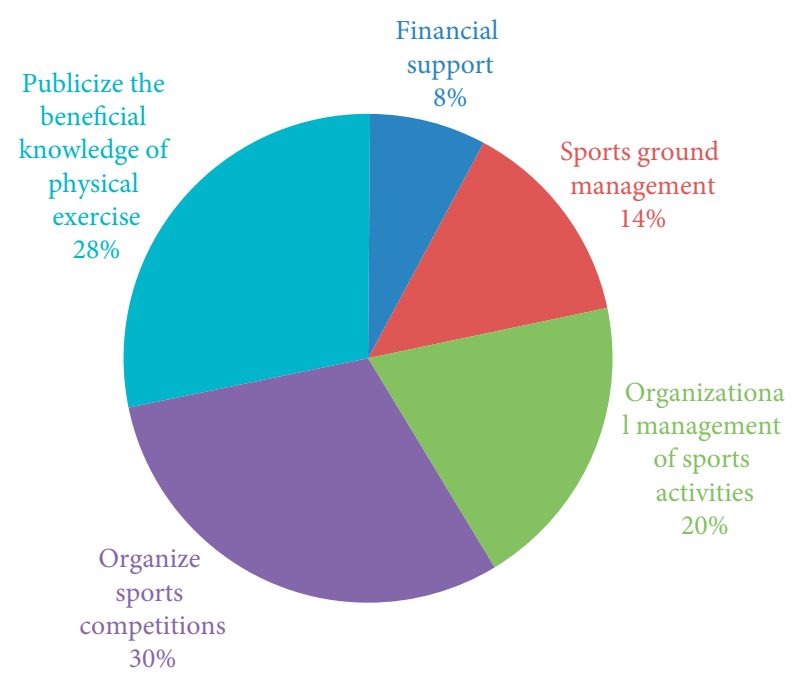

FIgURE 9: Sports public service supply map.

\subsubsection{People's Cognition of Sports Public Service in Nanchong City}

(1) Understanding Degree of Nanchong People. Through the investigation of 215 people's cognition of sports public service in Nanchong City, it is known that 83 of the 215 people know about the sports public service platform, accounting for $38.6 \%$; 78 people did not understand it, accounting for $36.2 \%$. The masses who know and do not know account for a large proportion, and the polarization is serious. We should popularize the knowledge of the sports public service platform for Nanchong people through various channels, such as community propaganda, government 
information push, and lectures. The understanding degree of Nanchong people is presented in Table 2.

(2) Statistics of Public Sports Activities in Nanchong City. Through the investigation on the frequency of sports activities of 215 people randomly selected in Nanchong City, it can be seen that 38 people have a lot of activities, accounting for $17.7 \%$; there are 34 people with few activities, accounting for $15.8 \%$; there were 44 people without related activities, accounting for $20.5 \%$. According to the data, the proportion of sports activities is $20.5 \%$, which shows that sports public services have not been fully promoted, and there are still no related sports activities in most areas. The statistics of public sports activities in Nanchong City is presented in Table 3.

\subsection{Present Situation of Sports Public Service Construction in Nanchong City}

4.2.1. Venue Provided. According to Figure 10, it is known that there are five departments, including shopping malls, communities, neighborhood committees, sports departments, and subdistrict offices, which provide venues for sports activities in Nanchong City, among which sports departments provide venues accounting for $37 \%$, providing advantages for sports public services of Nanchong citizens.

\subsubsection{Expenditure of Sports Public Service in Nanchong City}

(1) Funding Input. It can be intuitively known from Figure 11 that the sports public service funds provided by government departments account for $55.57 \%$ at most, and social welfare organizations account for the least investment. In order to alleviate the financial difficulties of sports public services in Nanchong City, donations can be made for social welfare activities, such as organizing charity sales and performances, so as to provide activity funds for sports activities in Nanchong City, thus having the ability to organize activities, making Nanchong citizens more convenient for sports, and improving the efficiency and satisfaction of sports public services.

(2) Use of Funds. It can be seen from Figure 12 that the cost of paying the venue accounts for $26 \%$. In order to alleviate the financial difficulties, the cost of paying the venue can be slightly adjusted through multiparty coordination, and the maximum proportion of organizing activities is $30 \%$.

4.2.3. Insufficient Development Status. According to the analysis of the development of sports public service in Nanchong City, we know that there are some shortcomings as follows: scarcity of venues, insufficient funds, shortage of activists, and scarcity of professional guidance personnel, weak sports awareness, large labor costs, and others. Among them, the scarcity of professionals is the most serious. In order to alleviate the related problems, sports safety guidance majors can be opened in some universities so as to train professional sports guidance personnel to prevent the harm caused by wrong sports actions. Among them, aiming at the
TABle 2: Understanding degree of Nanchong city.

\begin{tabular}{lcc}
\hline Degree of understanding & Number of people & Proportion (\%) \\
\hline Understand & 83 & 38.6 \\
General & 54 & 25.1 \\
Do not understand & 78 & 36.2 \\
Summation & 215 & 100 \\
\hline
\end{tabular}

TABLE 3: Number of public sports activities in Nanchong city.

\begin{tabular}{lcc}
\hline Number of activities & Number of people & Proportion (\%) \\
\hline A lot & 38 & 17.7 \\
More & 20 & 9.3 \\
General & 47 & 21.9 \\
Less & 32 & 14.9 \\
Very few & 34 & 15.8 \\
No & 44 & 20.5 \\
Total & 215 & 100 \\
\hline
\end{tabular}

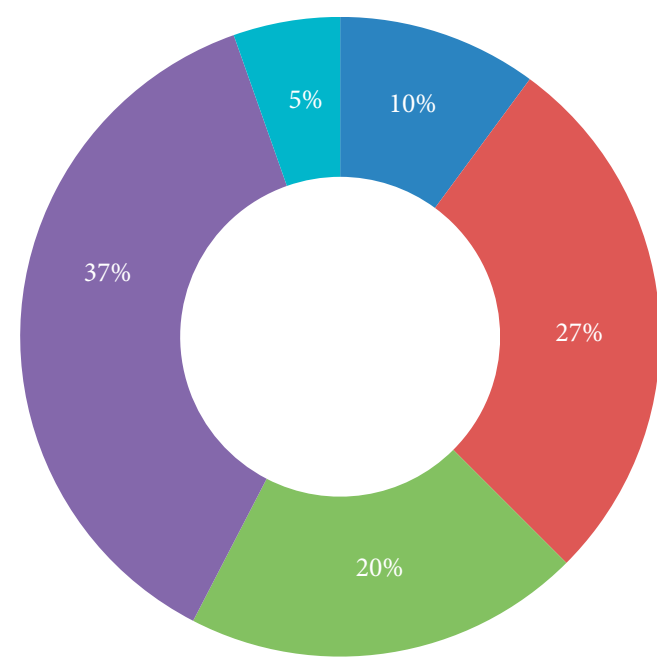

$$
\begin{aligned}
& \text { Provided by shopping malls } \\
& \text { Community provision } \\
& \text { Neighborhood Committee construction } \\
& \text { Construction of sports department } \\
& \text { Sub-district office }
\end{aligned}
$$

Figure 10: Proportion of site provision.

problems of weak sports awareness and shortage of activists, the sports public service platform can be developed in Nanchong City in an all-round way so that Nanchong citizens can have a deeper understanding of the sports public service platform, as shown in Figure 13.

\subsubsection{Number of Professional Sports Instructors in Various} Places from 2015 to 2019. According to the six regions selected in Table 4, since 2015-2019, the number of registered sports professional instructors in Chengdu, Nanchong, Yibin, Zigong, Guangyuan, Aba, and other places has increased year by year, which is embodied in the increase of citizens' awareness of sports and their participation in sports activities. Among them, the major of the registered sports in Nanchong has developed well. Combined with Figure 14, it can be seen that the related aspects in Chengdu are 


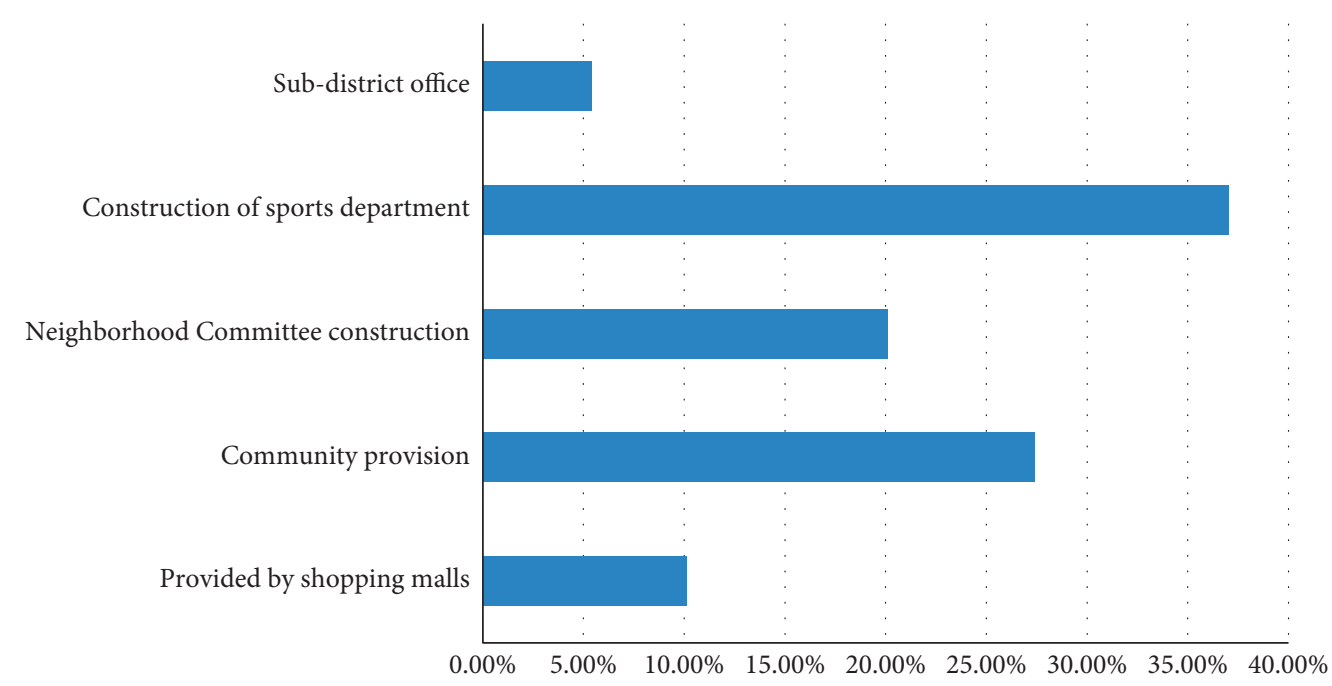

Figure 11: Proportion of fund input.

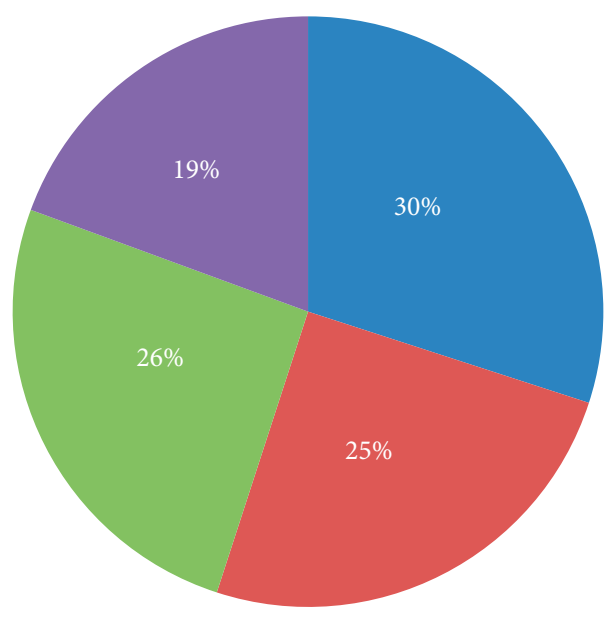

- Organize activities

- Purchase appliances

- Pay for the venue

- Costs of caretakers

Figure 12: Proportion of funds used.

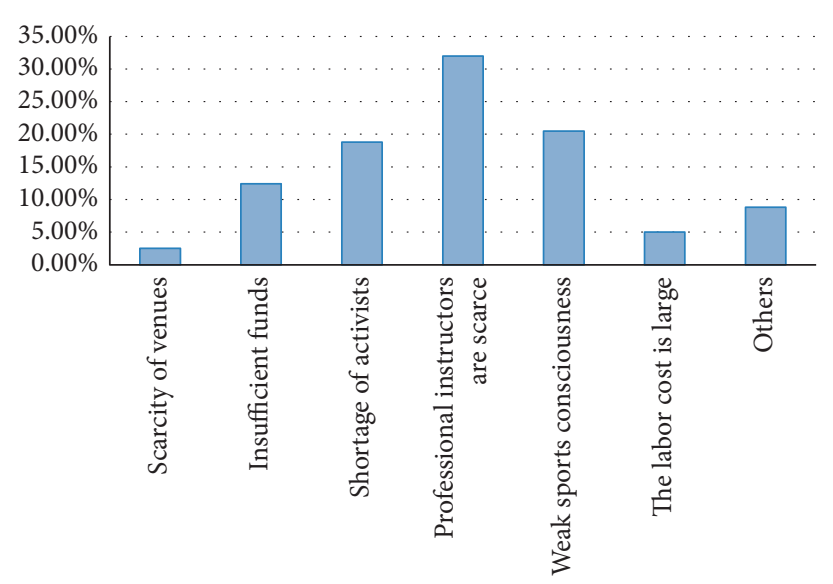

FIGURE 13: Underdevelopment factor chart. 
TABLE 4: Statistical table of registered sports professional guidance.

\begin{tabular}{lccccc}
\hline Region & $\begin{array}{c}\text { Number of people in } \\
\text { 2015 }\end{array}$ & $\begin{array}{c}\text { Number of people in } \\
2016\end{array}$ & $\begin{array}{c}\text { Number of people in } \\
2017\end{array}$ & $\begin{array}{c}\text { Number of people in } \\
2018\end{array}$ & $\begin{array}{c}\text { Number of people in } \\
2019\end{array}$ \\
\hline Chengdu & 5 & 10 & 17 & 20 & 24 \\
Nanchong & 6 & 9 & 14 & 16 & 14 \\
Yibin & 4 & 6 & 13 & 10 & 19 \\
Zigong & 4 & 8 & 12 & 11 & 16 \\
Guangyuan & 5 & 7 & 9 & 9 & 19 \\
Aba prefecture & 2 & 4 & & 16 \\
\hline
\end{tabular}

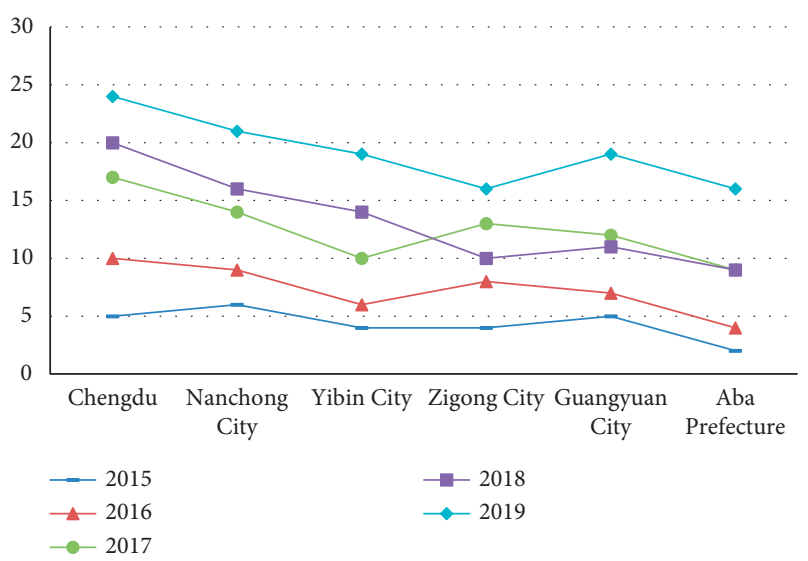

FIGURE 14: Comparison of registered sports professionals in six cities.

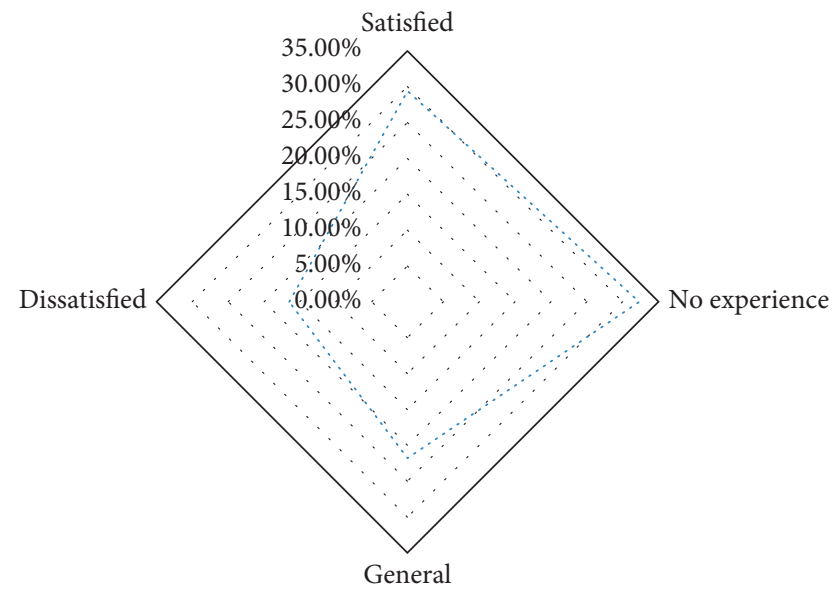

FIGURE 15: Investigation on the satisfaction of citizens in Nanchong city.

developing rapidly, and the development speed of related aspects in Nanchong is closely followed. It can be seen that the sports public service platform is widely promoted in Chengdu and Nanchong, and its awareness is higher than that of other urban areas surveyed.

4.2.5. Nanchong Citizens Satisfied with the Sports Public Service Platform. By inquiring 170 citizens randomly interviewed in Nanchong City, the largest proportion of people without experience was $32.3 \%$, which was $29.4 \%$ higher than that with satisfaction. Most of the surveyed
TABLE 5: Satisfaction questionnaire.

\begin{tabular}{lcc}
\hline Options & Number of people & Proportion (\%) \\
\hline Satisfied & 50 & 29.4 \\
No experience & 55 & 32.3 \\
General & 37 & 21.8 \\
Dissatisfied & 28 & 16.5 \\
\hline
\end{tabular}

people have not experienced the services brought by the sports public service platform, which shows that the sports public service has not been widely promoted in Nanchong City, and the benefits of the masses are not high. Combined with Figure 15 and Table 5, it can be seen that the platform and services are satisfactory among most people, and the platform should be upgraded and improved according to the limitations of the platform to provide better services for Nanchong citizens. Through related simulations, it can be seen that the current problems in Nanchong's public sports services include insufficient public awareness of sports public services, insufficient sports activities, insufficient sports facilities, and insufficient funding and high costs.

\section{Conclusion}

In view of the multiobjective optimization of sports public service in Nanchong City, the establishment and analysis of the information platform were carried out. The main content includes intelligent venues, information platform, sports safety, and other topics for research and application. In the platform construction, the service efficiency is constantly rising, and citizens need to constantly improve their civic awareness. Urban construction needs citizens to improve their service awareness and improve the utilization rate of urban sports services. In the future, further works will focus on the study of the use efficiency of service facilities and continuously improve the utilization rate of resources. The article improves the efficiency and public service of the sports public platform by establishing and analyzing the information platform of the sports public service in Nanchong. In response to the number of activities and funding issues raised in this article, the lack of professional sports coaches and other issues need to be improved in order to promote the good development of the city's public services and promote public sports.

\section{Data Availability}

The experimental data used to support the findings of this study are available from the corresponding author upon request. 


\section{Conflicts of Interest}

The authors declare that they have no conflicts of interest regarding this work.

\section{Acknowledgments}

This work was sponsored in part by Nanchong City Philosophy and Social Science Research Planning Project (NC2019B181).

\section{References}

[1] K. Deb, S. Agrawal, A. Pratap, and T. Meyarivan, "A fast elitist non-dominated sorting genetic algorithm for multi-objective optimization: NSGA-II," in Proceedings of the International Conference on Parallel Problem Solving from Nature, vol. 20, no. 03, pp. 37-41, Paris, France, September 2000.

[2] J. Horn, N. Nafpliotis, and D. E. Goldberg, "A niched Pareto genetic algorithm for multi-objective optimization[C]// evolutionary computation," in Proceedings of the 1994. Proceedings of the First IEEE Conference on IEEE World Congress on Computational Intelligence, vol. 32, no. 09, pp. 11-15, IEEE, Orlando, FL, USA, July 1994.

[3] K. Deb, L. Thiele, M. Laumanns, and E. Zitzler, "Scalable test problems for evolutionary multiobjective optimization," in Evolutionary Multiobjective Optimization. Advanced Information and Knowledge Processing, A. Abraham, L. Jain, and R. Goldberg, Eds., Springer, London, pp. 105-145, 2005.

[4] C. A. Coello Coello, "Evolutionary multi-objective optimization: a historical view of the field," IEEE Computational Intelligence Magazine, vol. 1, no. 1, pp. 28-36, 2006.

[5] F. Altiparmak, M. Gen, L. Lin, and T. Paksoy, "A genetic algorithm approach for multi-objective optimization of supply chain networks," Computers \& Industrial Engineering, vol. 51, no. 1, pp. 196-215, 2006.

[6] J. Cai-Xing, "Establishing a perfect sports public service system," Sport Science Research, vol. 28, no. 02, pp. 1-13, 2008.

[7] G. Y. Feng, "Equalization of sports public service and choice of relevant fiscal policy," Journal of Shanghai University of Sport, vol. 31, no. 06, pp. 26-31, 2007.

[8] L. I. Jian-Guo, "Basis of a sports power-construction of sports public service system," Sport Science Research, vol. 30, no. 04, pp. 15-18, 2009.

[9] L. I. Jing, "Study on sports public service system," Journal of Nanjing Institute of Physical Education, vol. 23, no. 01, pp. $62-65,2009$.

[10] J. Yao and X. Ding, "VEC-Model-Based sports public service analysis," International Journal of Digital Content Technology and its Applications, vol. 6, no. 17, pp. 226-234, 2012.

[11] L. I. Pei-Feng and Q. M. Zhu, "Design and implementation of campus information platform based on web services," Computer Engineering and Design, vol. 27, no. 19, pp. 35643567, 2006.

[12] Y. U. Li-Ping, "Equality of sports public service in China," Journal of Wuhan Institute of Physical Education, vol. 45, no. 07, pp. 31-35, 2011.

[13] W. Cheng, J. Y. H. Fuh, A. Y. C. Nee, Y. S. Wong, H. T. Loh, and T. Miyazawa, "Multi-objective optimization of partbuilding orientation in stereolithography," Rapid Prototyping Journal, vol. 1, no. 4, pp. 12-23, 1995.

[14] W. T. Jia, J. L. Hao, H. F. Liu, and H. O. N. G. liang, "Research to equalization of sports public service under the law," Journal of Nanjing Institute of Physical Education, vol. 23, no. 03, pp. 78-81, 2009.

[15] J. Liu, H. Yong, and X. Zhou, "Cloud computing science and technology information service system platform design," Bulletin of Science and Technology, vol. 28, no. 10, pp. 19-21, 2012.

[16] X. Tao and H. W. Chen, "Evolutionary algorithms for multiobjective optimization and decision-making problems," Engineering and Science, vol. 4, no. 2, pp. 59-68, 2002.

[17] M. Gong, L. Jiao, D. Yang, and W. Ma, "Research on evolutionary multi-objective optimization algorithms," Journal of Software, vol. 20, no. 2, pp. 112-134, 2009.

[18] L. I. Li, "Sports public service: the demand of sports business development on public finance," China Sport Science, vol. 30, no. 06 , pp. 53-58+80, 2010.

[19] E. L. Zhang, "The research review on Chinese sports public service and sports public policy," Journal of Hebei Institute of Physical Education, vol. 26, no. 01, pp. 8-11, 2012.

[20] X. P. Qin, J. Wang, and L. U. Chang-Fen, "A study on the way of sports public service equalization based on comparative analysis," Journal of Beijing Sport University, vol. 33, no. 02, pp. 15-18, 2010.

[21] J. H. Shen, "Demand for shanghai sports public service," Sport Science Research, vol. 02, pp. 37-41, 2008.

[22] C. X. Wang, "Comparison and revelation of sports public service," Sport Science Research, vol. 02, pp. 27-31, 2008.

[23] L. Q. Wang, G. U. Jian-Wei, Y. J. Cao, Y. U. Li, C. X. Guo, and B. Liu, "Design and implementation of power real-time information platform based on CIM/CIS," Proceedings of the Chinese Society of Universities for Electric Power System and its Automation, vol. 20, no. 01, pp. 46-51, 2008.

[24] R. J. Kauffman and L. Lally, "A value platform analysis perspective on customer access information technology[J]," Decision Sciences, vol. 25, no. 5-6, pp. 767-794, 2010. 